\title{
Predominant emphysema phenotype in chronic obstructive pulmonary disease patients
}

\author{
P. Boschetto*, M. Miniati", D. Miotto*, F. Braccioni*, E. De Rosa*, I. Bononi*, A. Papi*, M. Saetta ${ }^{+}$, \\ L.M. Fabbri", C.E. Mapp*
}

Predominant emphysema phenotype in chronic obstructive pulmonary disease patients. P. Boschetto, M. Miniati, D. Miotto, F. Braccioni, E. De Rosa, I. Bononi, A. Papi, M. Saetta, L.M. Fabbri, C.E. Mapp. (C) ERS Journals Ltd 2003.

ABSTRACT: Patients with fixed airflow limitation are grouped under the heading of chronic obstructive pulmonary disease (COPD). The authors investigated whether COPD patients have distinct functional, radiological and sputum cells characteristics depending on the presence or absence of emphysema.

Twenty-four COPD outpatients, 12 with and 12 without emphysema on highresolution computed tomography scan of the chest, were examined. Patients underwent chest radiography, pulmonary function tests and sputum induction and analysis.

Subjects with documented emphysema had lower forced expiratory volume in one second (FEV1), FEV1/forced vital capacity ratio, and lower carbon monoxide diffusion constant (KCO), compared with subjects without emphysema. Chest radiograph score of emphysema was higher, chest radiograph score of chronic bronchitis was lower, and the number of sputum lymphocytes was increased in patients with emphysema, who also showed a negative correlation between $K \mathrm{CO}$ and pack-yrs.

Chronic obstructive pulmonary disease patients with emphysema, documented by high-resolution computed tomography scan, have a different disease phenotype compared with patients without emphysema. Identification of chronic obstructive pulmonary disease-related phenotypes may improve understanding of the natural history and treatment of the disease.

Eur Respir J 2003; 21: 450-454.

\begin{abstract}
*Dept of Experimental and Clinical Medicine, University of Ferrara, Ferrara, "Institute of Clinical Physiology, CNR, Pisa, "Dept of Medicine, Oncology and Radiology, Section of Respiratory Diseases, University of Modena \& Reggio Emilia, Modena, and ${ }^{+}$Dept of Environmental Medicine and Public Health, University of Padova, Padova, Italy.
\end{abstract}

Correspondence: C.E. Mapp, Dipartimento di Medicina Clinica e Sperimentale, Sezione di Igiene e Medicina del Lavoro, Via Fossato di Mortara 64/b, 44100 Ferrara, Italy.

Fax: 390532205066

E-mail: map@dns.unife.it

Keywords: Chronic obstructive pulmonary disease, computed tomography, emphysema

Received: June 62002

Accepted after revision: November 20 2002

This study was supported by the Italian Ministry of University and Research Consorzio Ferrararicherche.
Chronic obstructive pulmonary disease (COPD) is characterised by the progressive development of airflow limitation that is not fully reversible [1]. Chronic airflow limitation is caused by a mixture of small airways inflammatory disease, obstructive bronchiolitis and parenchymal destruction, and emphysema, the relative contributions of which vary from person to person [2].

Chronic inflammation causes remodelling and narrowing of the small airways and, theoretically, it responds to pharmacological treatment. Destruction of the lung parenchyma leads to the loss of alveolar attachments to the small airways and decreases lung elastic recoil. These changes, which are considered to be unresponsive to pharmacological treatment, diminish the ability of the airways to remain open during expiration.

COPD has a variable natural history and not all individuals follow the same course and have the same response to therapy. Patients with emphysema have the lowest survival rate and the highest rate of decline in pulmonary function among COPD patients [3]. Thus, it is clinically relevant to detect, in the diagnostic work-up of patients with COPD, individuals with emphysema, possibly by using noninvasive methods. Although it has become increasingly clear that lung computed tomography (CT), especially when performed with thin-section, high-resolution techniques, is the most accurate imaging method for detecting the extent and severity of emphysema [4], lung function and chest radiography are invariably obtained in the clinical assessment of COPD. Recently, the application of sputum induction and refined methods of sputum examination have provided the opportunity to examine cell and molecular markers of airway inflammation in COPD [5], contributing to the characterisation of lung inflammation in the disease $[6,7]$.

The aim of this study was to investigate, by using classical diagnostic tests, such as lung function tests, radiological examination and sputum analysis, whether COPD patients with documented emphysema at high-resolution computed tomography (HRCT) of the chest have a different disease phenotype compared with COPD patients without emphysema.

\section{Subjects and methods}

\section{Subjects}

COPD patients $(n=24)$ with fixed airflow limitation, i.e. forced expiratory volume in one second (FEV1) $<70 \%$ of predicted values and FEV1/forced vital capacity (FVC) ratio $<70 \%$, were examined both before and after $200 \mu \mathrm{g}$ of inhaled salbutamol (table 1). Chronic bronchitis was defined as cough 
Table 1.-Characteristics of the chronic obstructive pulmonary disease (COPD) patients divided according to the presence or absence of emphysema on high-resolution computed tomography examination ${ }^{\#}$

\begin{tabular}{lcc}
\hline $\begin{array}{l}\text { Characteristic/pulmonary } \\
\text { function response }\end{array}$ & Emphysema & $\begin{array}{c}\text { No } \\
\text { emphysema }\end{array}$ \\
\hline Age yrs & $68 \pm 2$ & $68 \pm 2$ \\
Sex M:F & $11: 1$ & $11: 1$ \\
Smoking history pack-yrs & $29 \pm 6$ & $36 \pm 7$ \\
Body mass index & $28 \pm 1.4$ & $26 \pm 0.8$ \\
Treatment & $11(91.6)$ & $7(58.3)$ \\
$\quad$ Inhaled steroids n (\%) & & \\
Inhaled bronchodilators n (\%) & $9(75)$ & $7(58.3)$ \\
$\quad$ Short-acting & $10(83.3)$ & $8(66.6)$ \\
$\quad$ Long-acting & $4(33.3)$ & $0(0)$ \\
$\quad$ Theophylline & $2(16.6)$ & $4(33.3)$ \\
Positive skin-prick test n $(\%)$ & $38 \pm 3 \%$ & $58 \pm 3$ \\
FEV1\% pred pre-bronchodilator & $40.69 \pm 3.3$ & $54.68 \pm 2.3$ \\
FEV1/FVC \% pre-bronchodilator & $129 \pm 8$ & $111 \pm 10$ \\
RV \% pred & $98 \pm 4$ & $95 \pm 4$ \\
TLC \% pred & $78.6 \pm 4.5^{*}$ & $104.2 \pm 4.8$ \\
IC \% pred & $112 \pm 6^{*}$ & $95 \pm 7$ \\
FRC \% pred & $48 \pm 8^{*}$ & $71 \pm 7$ \\
KCO \% pred & $120 \pm 25$ & $141 \pm 28$ \\
$\Delta$ FEV1 post-bronchodilator mL & $4.3 \pm 0.9$ & $5.4 \pm 1.1$ \\
$\Delta$ FEV1 post-bronchodilator \% pred &
\end{tabular}

Data are presented as mean \pm SEM. M: male; F: female; FEV1: forced expiratory volume in one s; $\%$ pred: $\%$ predicted; FVC: forced vital capacity; RV: residual volume; TLC: total lung capacity; IC: inspiratory capacity; FRC: functional residual capacity; KCO: carbon monoxide diffusion constant. ${ }^{\#}$ : score $>10$ indicated emphysema. *: $\mathrm{p}<0.05$ versus COPD patients with no emphysema; ${ }^{*} \mathrm{p}<0.005$ versus COPD patients with no emphysema.

and sputum production occurring on most days of the month for at least 3 months per year, during the 2 yrs before the study [2]. All subjects were recruited from the outpatient clinic of the Section of Respiratory Diseases of the University of Ferrara, Ferrara, Italy. The Ethics Committee of the University Hospital of Ferrara approved the study and all patients gave their written informed consent. COPD was diagnosed according to the criteria recommended by the European Respiratory Society [8]. All patients were in stable conditions at the time of the study and free from acute exacerbations of symptoms and upper respiratory tract infections in the 2 months preceding the study.

\section{Study design}

Emphysema was characterised using HRCT technique and a visual score $>10$ indicated emphysema [9]. Each patient underwent medical history, physical examination, pulmonary function tests, chest radiography, CT, skin-prick tests, induced sputum, and $\alpha_{1}$-antitrypsin measurement, since three of the patients were nonsmokers.

\section{Pulmonary function studies}

In each patient, lung volumes (Biomedin, Padova, Italy), the carbon monoxide diffusion constant $(K \mathrm{CO})$, by the singlebreath technique, end-exhaled nitric oxide (NO) (Nitric oxide A 280 analyser; Sievers, Boulder, CO, USA), arterial oxygen $\left(\mathrm{Pa}, \mathrm{O}_{2}\right)$ and carbon dioxide tension $\left(\mathrm{Pa}, \mathrm{CO}_{2}\right)$ (Instrumentations Laboratories, Milan, Italy) were measured as described previously [8], according to published guidelines [10-12].

\section{Chest radiography}

Chest radiographs (postero-anterior and lateral) were obtained with the patients in an upright position, holding their breath at full inspiration. A standard $2 \mathrm{~m}$ focus-to-film distance was used. Exposure time was kept as short as possible to reduce motion blurring and was usually within $0.05 \mathrm{~s}$. A fine lead grid (grid ratio 6) was used to reduce scattered X-rays, thereby enhancing film resolution. Chest radiographs were obtained within $48 \mathrm{~h}$ of pulmonary function studies and prior to the sputum inductions. Chronic bronchitis and emphysema scores, ranging 0-16, were calculated as described previously [9, 13]. Emphysema and chronic bronchitis scores have proved highly reproducible among different observers $[9,13]$.

\section{Computed tomography}

HRCT scans were performed at suspended full inspiration on a TOMOS 7000 scanner (Philips, Einthoven, The Netherlands), as described previously [9]. No contrast medium was infused. Technical parameters were $1 \mathrm{~mm}$ collimation, $120 \mathrm{kV}$ peak, $160 \mathrm{~mA}$, and 3-s scanning time. A visual score of emphysema was derived according to the method of SAKAI et al. [14] and a cumulative score of emphysema, ranging 0-72 was obtained, as described previously [9].

\section{Induced sputum}

Sputum was collected after bronchodilator inhalation and analysed as described previously [8]. To make the procedure safer, sputum was induced and spirometric measurements were performed as reported previously [15]. Increasing concentrations of hypertonic saline were nebulised with an ultrasonic nebuliser (Mistogen EN 145 electronic nebuliser; Mistogen Equipment Co., Oakland, CA, USA).

\section{Atopic status}

Skin-prick tests to 12 common aeroallergens were performed according to a standard protocol [8].

\section{$\alpha_{1}$-antitrypsin}

A peripheral blood sample was drawn and the serum was separated. Antibodies against human $\alpha_{1}$-antitrypsin were added to the serum and the intensity of the light diffused by suspended particles, resulting from the formation of the antigen/antibody complex, was measured with a nephelometric method (Beckman Instruments, Milan, Italy).

\section{Statistical analysis}

Group data are expressed as mean \pm SEM or as median and interquartile range when appropriate. Differences between groups were analysed using the Mann-Whitney U-test and Bonferroni's correction was applied when indicated. Categorical values were analysed using Fisher's exact test. Spearman's rank correlation test was used to examine the association between lung and radiological data and cigarette smoking and/ or sputum cells. To define the predictive value of the variables analysed, receiver-operating characteristic (ROC) curve analysis was performed for a comparison of ranked variables. The area under the ROC curves was determined and a value of $>0.80$ was accepted as indicating good discrimination [16]. ROC curve analysis also allowed selection of the best cut-off 


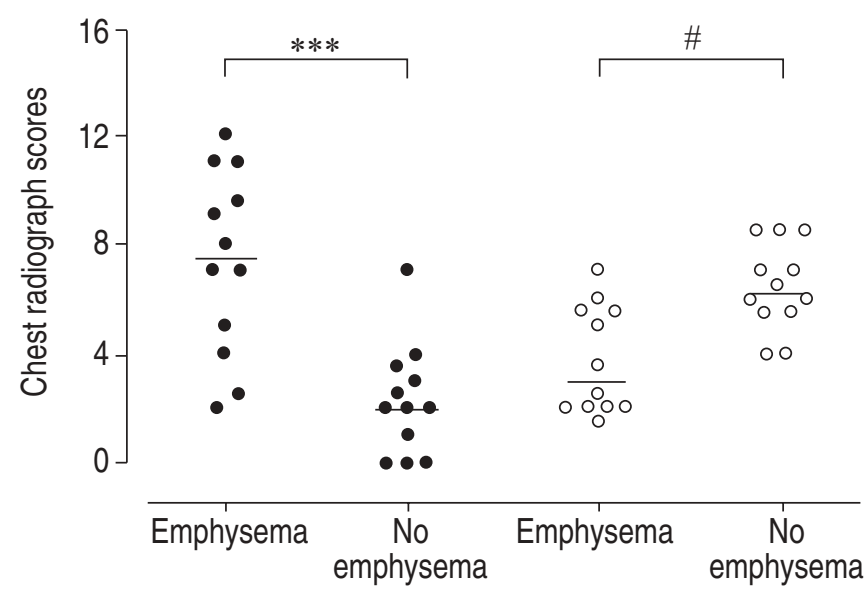

Fig. 1.-Chest radiograph scores of emphysema (O) and chronic bronchitis $(\bigcirc)$ in chronic obstructive pulmonary disease patients, divided according to the presence or absence of emphysema. The horizontal solid bars indicate the median values for each group. ***: $\mathrm{p}<0.001 ;{ }^{\#}: \mathrm{p}<0.005$.

point of the variables studied by analysing their sensitivity versus one minus specificity. A p-value of $<0.05$ was accepted as significant.

\section{Results}

\section{Clinical findings}

Table 1 shows the characteristics of the subjects examined. There was no significant difference in age, smoking history and body mass index between COPD patients with emphysema and patients with no emphysema. In all subjects, $\alpha_{1}$-antitrypsin values were within the normal range $\left(83-199 \mathrm{mg} \cdot \mathrm{dL}^{-1}\right)$. Dyspnoea, graded according to the Medical Research Council dyspnoea scale [17], was mild and similar in the two groups. Three of the 12 COPD patients with and eight of the 12 without emphysema had symptoms of chronic bronchitis.

\section{Pulmonary function findings}

There was no significant difference in total lung capacity (TLC; \% pred), exhaled NO, arterial blood gases and response to inhaled salbutamol between the COPD patients with and without emphysema (table 1). Emphysema patients had a significantly lower FEV1 (\% pred), FEV1/FVC ratio (\%) and KCO ( $\%$ pred) than patients with no emphysema. For similar values of TLC in the two groups, inspiratory capacity (IC; \% pred) was significantly lower, whereas functional residual capacity (FRC; \% pred) was significantly higher in COPD patients with emphysema, indicating greater pulmonary hyperinflation. Residual volume (RV; \% pred) was higher $(\mathrm{p}=0.09)$ in the emphysema group. In this group, a negative correlation was found between $\mathrm{KCO}$ and cigarettes smoked $(\mathrm{r}=-0.83 ; \mathrm{p}<0.01)$.

\section{Chest radiography}

As expected from the selection criteria, COPD patients with emphysema had a significantly higher chest radiograph score of emphysema (7.5 (4.5-10) versus 2 (0.5-3), $\mathrm{p}<0.001$; fig. 1) and a lower chest radiograph score of chronic bronchitis $(3$ (2-5.5) versus $6(5.5-5.7) ; \mathrm{p}<0.005$; fig. 1$)$ than patients with no emphysema.
Table 2.-Sputum cells in chronic obstructive pulmonary disease (COPD) patients divided according to the presence or absence of emphysema on high-resolution computed tomography examination

\begin{tabular}{lcc}
\hline Cells & $\begin{array}{c}\text { COPD patients } \\
\text { with emphysema }\end{array}$ & $\begin{array}{c}\text { COPD patients with } \\
\text { no emphysema }\end{array}$ \\
\hline $\begin{array}{l}\text { Total nonsquamous } \\
\text { cells } 1 \times 10^{4} \cdot \mathrm{mL}^{-1}\end{array}$ & $48(23-111)$ & $60(17-359)$ \\
Macrophages \% & $30.6(15.0-46.3)$ & $10.2(4.7-28.0)$ \\
Neutrophils \% & $64.9(49.6-82.0)$ & $83.6(65.5-91.4)$ \\
Eosinophils \% & $2.4(1-3)$ & $2.5(1.2-6.3)$ \\
Lymphocytes \% & $1.5(0.7-3.5)^{*}$ & $0.2(0-1.0)$ \\
\hline
\end{tabular}

Data are presented as median (interquartile range). ${ }^{*}: \mathrm{p}<0.05$ versus COPD patients with no emphysema.

\section{Sputum findings}

Patients with emphysema had more sputum lymphocytes than patients with no emphysema. No other significant differences were observed (table 2). When all COPD patients were considered together, sputum lymphocytes correlated negatively with IC $\%$ pred $(\mathrm{r}=-0.46, \mathrm{p}<0.05)$ and positively, albeit not to a significant extent, with the HRCT score of emphysema $(\mathrm{r}=0.40, \mathrm{p}=0.06)$. In emphysematous patients, a positive correlation was found between the HRCT score of emphysema and sputum neutrophils ( $\mathrm{r}=0.60, \mathrm{p}<0.05$; fig. 2).

\section{Receiver-operating characteristic curve analysis}

FEV1, chest radiograph score of emphysema and sputum lymphocytes were shown to be the best predictive factors of emphysema. For FEV1 \% pred, the area under the ROC curves was 0.89 , for emphysema score it was 0.90 , and for the percentage of lymphocytes in sputum it was 0.81 . For FEV1 $\%$ pred, the best cut-off point was $49 \%$ pred, which had a sensitivity of 0.83 and a specificity of 0.83 . For the chest radiograph score of emphysema, the best cut-off point was 4.0 , which had a sensitivity of 0.75 and a specificity of 0.80 . For sputum lymphocytes, the best cut-off point was $1 \%$, which had a sensitivity of 0.67 and a specificity of 0.83 .

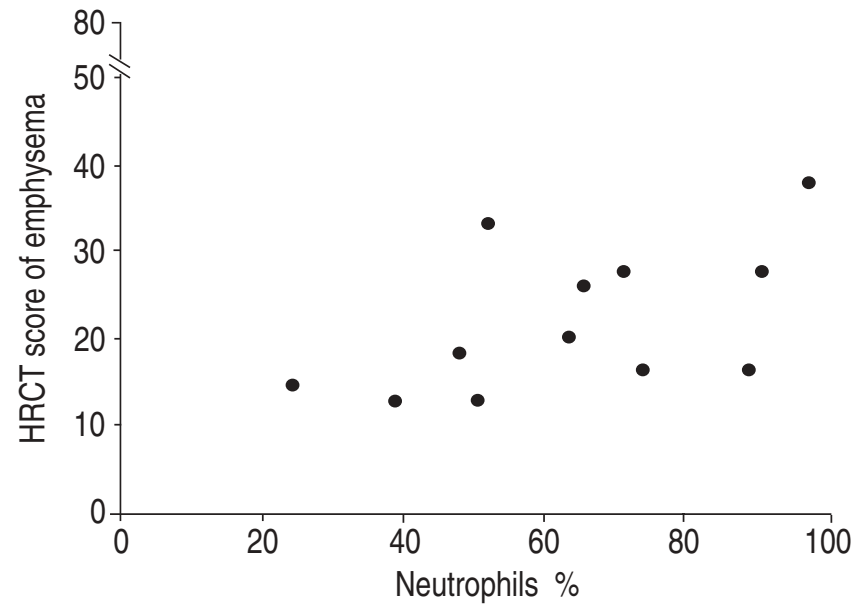

Fig. 2.- Relationship between high-resolution computed tomography (HRCT) score of emphysema and percentage of sputum neutrophils (Spearman's rank correlation: $\mathrm{p}<0.05, \mathrm{r}=0.60$ ) in chronic obstructive pulmonary disease patients with emphysema. 


\section{Discussion}

In this study, the authors have shown that patients with fixed airflow limitation (COPD) have a different disease phenotype, depending on the presence or absence of emphysema on chest HRCT. Patients were selected on the basis of functional criteria, i.e. $\mathrm{FEV} 1<70 \%$ pred and $\mathrm{FEV} 1 / \mathrm{FVC}$ ratio $<70 \%$ both before and after inhaled bronchodilator. These inclusion criteria were used as they define most of the COPD patients involved. COPD subjects with emphysema had lower FEV1, lower FEV1/FVC ratio, lower KCO, higher chest radiograph scores of emphysema, lower chest radiograph scores of chronic bronchitis, and an increased number of lymphocytes in induced sputum.

These findings of a higher degree of airflow obstruction in patients with emphysema are in agreement with the results of previous studies that focused on the relationship between severity and extent of emphysema and lung function data [18-22]. By contrast, these findings may appear to conflict with those of FLETCHER et al. [23], who found no differences in clinical and lung function features between emphysema and chronic bronchitis patients. However, they examined a different population: patients were younger, 20\% exhibited reversible airflow limitation after inhaled bronchodilator, and the majority had a history of wheezing.

In the present study, a reduction in $\mathrm{KCO}$ was found in COPD patients with emphysema. The reduction of CO diffusing capacity is a physiological abnormality known to be associated with pulmonary emphysema, and it has been shown to correlate with the extent of emphysema [24]. In emphysematous patients, a negative correlation between $\mathrm{KCO}$ and pack-yrs was also observed, which supports and extends the findings of other studies [25, 26] that have shown a negative correlation between lung function and pack-yrs even in asymptomatic subjects [26]. The emphysematous subjects in this study exhibited baseline values of IC and FRC smaller and greater, respectively, than those of patients with no emphysema. As baseline TLC was not different between the two groups, these data reflect a greater pulmonary hyperinflation in emphysematous patients. In these patients, RV and TLC were higher, but not significantly so, thus indicating that subjects with emphysema do not have a pure emphysema phenotype and, therefore, lack the fairly uniform pattern of abnormal pulmonary function tests characteristic of emphysema. The lack of significant differences in these variables, however, does not exclude meaningful differences.

In the present COPD patients, the distinction between emphysema and no emphysema on the HRCT was based on a cut-off of 10 of the applied visual score, which ranged from $0-72$. According to previous findings [9], the authors were confident that an HRCT score of emphysema that did not exceed $14 \%$ of the maximal score obtainable, was compatible with no or with only trivial emphysema.

With regard to imaging tests, it has been demonstrated that conventional chest radiography is useful in the clinical evaluation of emphysema [9]. The fact that, in this study, a higher chest radiograph score of emphysema and a lower score of chronic bronchitis were present in patients with emphysema, confirms that this examination is useful to discriminate the two phenotypes, i.e. emphysema and no emphysema. When all the patients were considered together, chest radiograph scores of chronic bronchitis showed a negative correlation with the HRCT emphysema score (data not shown), suggesting that the features of bronchial and/or bronchiolar inflammation are predominant in patients with no emphysema. In this study, symptoms of chronic bronchitis were present in the majority of patients without emphysema, but only in three subjects with emphysema, confirming that hypersecretion of mucus is present more in patients with no or trivial emphysema [22]. Three subjects without emphysema on HRCT scan and without symptoms of chronic bronchitis were also observed. These subjects had a high radiograph score of chronic bronchitis, 6.5, 5.5 and 8.5 (scores ranging 1.5-8.5), suggesting that chest radiography detects bronchial and/or bronchiolar inflammation better than the symptoms. Another possible explanation for this lack of relationship between symptoms and chest radiograph is a different time course for the two events, with early radiological changes later followed by symptoms.

This study, using induced sputum, demonstrated a slight but significant increase in the number of sputum lymphocytes in patients with emphysema. No differences were observed in other sputum inflammatory cells, supporting the evidence that these patients did not have a pure component of lung parenchymal destruction, i.e. a pure emphysema phenotype, and also an airway inflammatory component. Lymphocytes, particularly CD8+ cytolytic T-cells, have been recognised recently as the predominant cells in the alveolar wall of smokers with emphysema [27]. The results, obtained by a noninvasive method, such as sputum induction, confirm this finding. Moreover, a negative correlation was found between sputum lymphocytes and IC, which typically decreases in emphysema due to pulmonary hyperinflation. Taken together, all the above data suggest that lymphocytes are the inflammatory cells best associated with emphysema and they may be obtained by sputum induction. Therefore, it could be useful to introduce this noninvasive method into the regular work-up of COPD patients, given that it is also simple and safe [28]. Finally, regarding sputum differential cell counts, it should also be noted that there was a correlation between the HRCT score of emphysema and the number of neutrophils. This finding seems to support the hypothesis that neutrophils are implicated in the severe stage of COPD, as other studies have also suggested [29, 30].

Although in COPD patients the two components of airflow limitation, small airway disease (obstructive bronchiolitis) and parenchymal destruction (emphysema), often coexist, it could be clinically relevant to distinguish subjects with predominant emphysema phenotype.

In conclusion, the authors showed that forced expiratory volume in one second, chest radiograph score of emphysema and sputum lymphocytes are the three indices that better distinguish emphysema from nonemphysema patients. Such distinction could be useful in clinical practice, may improve understanding of the natural history of the disease, and may help to focus treatment strategies for different chronic obstructive pulmonary disease phenotypes, as, for example, the more the lung destructive component is widespread, the less antiinflammatory drugs are expected to be of benefit.

Acknowledgements. The authors would like to thank G. Caramori, C. Piola, A. Potena and L. Ballarin for their expert collaboration, A. Rambaldi and E. Forini for helping in the statistical analysis and O. Di Maria for technical assistance.

\section{References}

1. American Thoracic Society. Standards for the diagnosis and care of patients with chronic obstructive pulmonary disease. Am J Respir Crit Care Med 1995; 152: S77-S121.

2. Pauwels RA, Buist AS Calverley PM, Jenkins CR, Hurd SS Global strategy for the diagnosis, management, and prevention of chronic obstructive pulmonary disease: NHLBI/WHO 
Global Initiative for Chronic Obstructive Lung Disease (GOLD) Workshop summary. Am J Respir Crit Care Med 2001; 163: 1256-1276.

3. Burrows B, Bloom JW, Traver GA, Cline MG. The course and prognosis of different forms of chronic airways obstruction in a sample from the general population. N Engl J Med 1987; 317: 1309-1314.

4. Thurlbeck WM, Muller NL. Emphysema: definition, imaging, and quantification. AJR Am J Roentgenol 1994; 163 : 1017-1025.

5. Peleman RA, Rytila PH, Kips JC, Joos GF, Pauwels RA. The cellular composition of induced sputum in chronic obstructive pulmonary disease. Eur Respir J 1999; 13: 839843.

6. Barnes PJ. Chronic obstructive pulmonary disease. $N$ Engl $J$ Med 2000; 343: 269-280.

7. Papi A, Romagnoli M, Baraldo S, et al. Partial reversibility of airflow limitation and increased exhaled NO and sputum eosinophilia in chronic obstructive pulmonary disease. $\mathrm{Am}$ J Respir Crit Care Med 2000; 162: 1773-1777.

8. Siafakas NM, Vermeire P, Pride NB, et al. Optimal assessment and management of chronic obstructive pulmonary disease (COPD). The European Respiratory Society Task Force. Eur Respir J 1995; 8: 1398-1420.

9. Miniati M, Filippi E, Falaschi F, et al. Radiologic evaluation of emphysema in patients with chronic obstructive pulmonary disease. Chest radiography versus high resolution computed tomography. Am J Respir Crit Care Med 1995; 151: 1359-1367.

10. Quanjer PhH, Tammeling GJ, Cotes JE, Pederson OF, Peslin $\mathrm{R}$, Yernault J-C. Lung volumes and forced ventilatory flows. Eur Respir J 1993; 6: Suppl. 16, 5-40.

11. Cotes JE, Chinn DJ, Quanjer PhH, Roca J, Yernault J-C. Standardization of the measurement of transfer factor (diffusing capacity). Eur Respir J 1993; 6: Suppl. 16, 41-52.

12. Kharitonov S, Alving K, Barnes PJ. Exhaled and nasal nitric oxide measurements: recommendations. The European Respiratory Society Task Force. Eur Respir J 1997; 10: 1683-1693.

13. Milne ENC, Pistolesi M. Detecting and quantifying chronic bronchitis and emphysema. In: Milne ENC, Pistolesi M, eds. Reading the Chest Radiograph. A Physiologic Approach. Mosby, St. Louis, 1993; pp. 267-310.

14. Sakai F, Gamsu G, Im JG, Ray CS. Pulmonary function abnormalities in patients with CT-determined emphysema. J Comput Assist Tomogr 1987; 11: 963-968.

15. Rytila PH, Lindqvist AE, Laitinen LA. Safety of sputum induction in chronic obstructive pulmonary disease. Eur Respir J 2000; 15: 1116-1119.

16. Hanley JA, McNeil BJ. The meaning and use of the area under a receiver operating characteristic (ROC) curve. Radiology 1982; 143: 29-36.

17. Bestall JC, Paul EA, Garrod R, Garnham R, Jones PW, Wedzicha JA. Usefulness of the Medical Research Council
(MRC) dyspnoea scale as a measure of disability in patients with chronic obstructive pulmonary disease. Thorax 1999; 54: $581-586$.

18. Coxson HO, Rogers RM, Whittall KP, et al. A quantification of the lung surface area in emphysema using computed tomography. Am J Respir Crit Care Med 1999; 159: 851-856.

19. Park KJ, Bergin CJ, Clausen JL. Quantitation of emphysema with three-dimensional CT densitometry: comparison with two-dimensional analysis, visual emphysema scores, and pulmonary function test results. Radiology 1999; 211: 541547.

20. Burrows B, Fletcher CM, Heard BE, Jones NL, Wootliff JS. The emphysematous and bronchial types of chronic airways obstruction. A clinicopathological study of patients in London and Chicago. Lancet 1966; 1: 830-835.

21. Zompatori M, Fasano L, Battista G, Pacilli AM, Stopazzoni C, Cavina M. Role of emphysema in the etiology of functional impairment in patients with severe chronic obstructive pulmonary disease. Study with high resolution computerized tomography. Radiol Med (Turin) 1999; 97: 26-32.

22. Mitchell RS, Stanford RE, Johnson JM, Silvers GW, Dart G, George MS. The morphologic features of the bronchi, bronchioles, and alveoli in chronic airway obstruction: a clinicopathologic study. Am Rev Respir Dis 1976; 114: 137145.

23. Fletcher CM, Jones NL, Burrows B, Niden AH. American emphysema and British bronchitis. A standardized comparative study. Am Rev Respir Dis 1964; 90: 1-13.

24. Baldi S, Miniati M, Bellina CR, et al. Relationship between extent of pulmonary emphysema by high-resolution computed tomography and lung elastic recoil in patients with chronic obstructive pulmonary disease. Am J Respir Crit Care Med 2001; 164: 585-589.

25. Enright PL. Smoking, lung function, and atherosclerosis in the 5,000 elderly participants of the Cardiovascular Health Study. Am J Geriatr Cardiol 1994; 3: 35-38.

26. Burrows B, Knudson RJ, Cline MG, Lebowitz MD Quantitative relationships between cigarette smoking and ventilatory function. Am Rev Respir Dis 1977; 115: 195-205.

27. Majo J, Ghezzo H, Cosio MG. Lymphocyte population and apoptosis in the lungs of smokers and their relation to emphysema. Eur Respir J 2001; 17: 946-953.

28. Pizzichini E, Pizzichini MMM, Leigh R, Djukanovic R, Sterk PJ. Safety of sputum induction. Eur Respir $J$ 2002; 20: Suppl. 37, 9s-18s.

29. Retamales I, Elliott WM, Meshi B, et al. Amplification of inflammation in emphysema and its association with latent adenoviral infection. Am J Respir Crit Care Med 2001; 164: 469-473.

30. Di Stefano A, Capelli A, Lusuardi M, et al. Severity of airflow limitation is associated with severity of airway inflammation in smokers. Am J Respir Crit Care Med 1998; 158: 1277-1285. 